Article

\title{
Energy Efficiency in the Brazilian Pulp and Paper Industry
}

\section{Guilherme Fracaro $^{1{ }^{*} *}$, Esa Vakkilainen ${ }^{2}$, Marcelo Hamaguchi ${ }^{2}$ and Samuel Nelson Melegari de Souza ${ }^{1}$}

1 State University of Western Parana, University Street, 2069, Cascavel, Parana, Brazil; E-Mail: samuel.souza@unioeste.br

2 Lappeenranta University of Technology, Lappeenranta 20, FI-53581, Finland; E-Mails: esa.vakkilainen@lut.fi (E.V.); marcelo.hamaguchi@lut.fi (M.H.)

* Author to whom correspondence should be addressed; E-Mail: guilherme.fracaro@yahoo.com; Tel.: +55-45-3224-8233.

Received: 29 May 2012; in revised form: 16 August 2012 / Accepted: 21 August 2012 / Published: 17 September 2012

\begin{abstract}
Industrial energy efficiency has received increasing attention in many countries because of its importance in the pursuit of energy supply security, increased economic competitiveness and in the mitigation of greenhouse gases emissions. This paper aimed to evaluate the energy consumption development of the Brazilian pulp and paper industry through an energy decomposition analysis and an energy efficiency index approach over a 30 years period. An international comparison with other important paper-producing countries (i.e., Canada, United States of America, Finland and Sweden) was carried out. It was concluded that despite a significant increase in the energy efficiency levels, responsible for 5.6 PJ savings in electricity consumption and for 38.6 PJ savings in fuels consumption between 1979 and 2009, a saving potential of 7.8 PJ and 146.2 PJ related to the annual consumption of electricity and fuels, respectively, could be identified in the Brazilian pulp and paper industry. Among the countries evolved in the international comparison, both the Swedish and Finnish industries were the most efficient, followed by the Brazilian, American and Canadian, the latter being the only one where there was a reduction in the energy efficiency levels from 1979 to 2009.
\end{abstract}

Keywords: energy-efficiency; decomposition analysis; international comparison 


\section{Introduction}

Energy efficiency refers to a lower energy input to produce the same amount of services/useful output [1]. Energy is essential both to provide quality of life to mankind and as input in any production process. After the industrial revolution the Western economies have developed based on industrial production and an increasing energy per capita consumption. With the 1970s' oil crisis there was an increased interest in adopting energy savings and more energy efficient solutions in the industrialized world, for both economic and security of supply reasons. In the beginning of the 1990s the awareness of the consequences of global warming has emerged strongly as another important driving force for energy efficiency solutions. As manufacturing industries account for approximately one-third of global energy use [2], energy efficiency in industry has been claimed as one of the main cost-effective paths to the reduction of both energy consumption (according to the first law of thermodynamics the term "energy consumption" is a misnomer, because the total amount of energy is maintained, even if its form changes, however, this term is used in the paper referring to the useful energy demanded by the pulp and paper production process) and GHG emissions [3-7]. In fact according to the IEA it seems a necessary ingredient if we aim to stop the level of carbon dioxide in the atmosphere from reaching above 450 ppm [2].

The energy consumption of an industrial sector is determined by its activity level, sector structure and energy efficiency [8] and the use of some indicators can provide insights into levels of energy efficiency. These indicators can be useful in the evaluation of energy efficiency policies or in the development of policy goals, or even in the identification of potential savings. However, the usefulness of an energy efficiency indicator regards to its comparability [9]. A given industry can find energy savings potential in its production processes by comparing its own energy performance with the energy performances of competing industries, or even evaluate improvements on its energy performance during time. Furthermore, a cross-country comparison can help in evaluating or designing national energy policies, either for the whole economy or specific sectors. Potential energy savings can be classified as technical (e.g., based on a Best Available Technology, BAT), economic (which considers the cost-effectiveness of the available technologies) and market potential (in which barriers to technologies implementation are also considered) [10].

The various indicators used to monitor changes in energy efficiency can be classified into four main groups, i.e., thermodynamic (e.g., energy output/energy input), physical-thermodynamic (e.g., energy input/tonne of product), economic-thermodynamic (e.g., energy input/GDP) and economic indicators (e.g., energy input in terms of economic value/GDP) [1]. The most commonly energy efficiency indicators used in industry are related to the energy consumption per value added or to a specific energy consumption, SEC (e.g., energy consumption per tonne of product). The former has the disadvantage of making no distinction about changes in energy intensity due to structure changes or technical improvements while the latter allows to consider possible changes in products mix [8,11-13]. The use of SEC is claimed as a more suitable indicator for energy intensive industries, although it can be difficult to establish SEC's in highly integrated production processes [8,12-14].

Several attempts have been made in the literature to identify energy saving potentials in specific industrial sectors through international comparison, most of which are focused on energy intensive industries. 
Reference [14] presented a methodology for a cross-time and cross-country comparison of energy efficiency developments in the manufacturing industry based on the use of physical indicators. The methodology has a weighting scheme based on specific energy requirements to produce different products to calculate a physical production index (PPI), giving higher values to more energy intensive products. They also applied a decomposition analysis to measure the influences of changes in production activity, production mix and energy efficiency in the variation of energy consumed by an industrial sector (e.g., the pulp and paper sector).

Reference [15] presented an international comparison of energy intensive industries, in terms of both energy efficiency and $\mathrm{CO}_{2}$ emission performances based on best available technologies. The industries studied were chemical and petrochemical, iron and steel, non-metallic minerals, pulp, paper and printing, and non-ferrous metals. Still, there are other important publications in this field, e.g., $[9,16,17]$.

The pulp and paper sector is the fourth-largest industrial consumer of energy; it represented $6 \%$ of world industrial energy use in 2005 [2]. It is characterized as an intensive industry, in terms of both capital and energy, with a high minimum efficient scale of production [14,18,19]. There are ample studies of pulp and paper sector energy use. Many of those concentrate on comparing mills to each other [20] or try to define the gap between current and theoretical minimum energy consumption [21-24]. There are also a lot of studies of how to improve a single mill's energy efficiency [25-28]. Schumacher and Sathaye analysed India's pulp and paper industry historical trends and found that actually energy intensity had grow as the industry was more focused saving in capital investments and labour [29], Szabó et al. used specific electricity and heat consumptions for each product grade and assumed energy efficiency improvement to study global pulp and paper industry energy use development up to 2030 [19].

The aim of this work is firstly to identify reasons for decreases of pulp and paper industry energy use and secondly look at how changes in primary energy used as well as changes in production mix affect national energy intensity. How much of the energy efficiency improvement is due to the growth, due to the change of primary energy source and most importantly due to the energy efficiency measures in the existing industry. As Brazil is a country where continuous growth of pulp and paper industry is still occurring and reasonable data was available it was chosen to be the target country. Thirdly the aim was to evaluate the long-term energy efficiency development of Brazilian pulp and paper industry, identifying the main causes of its energy consumption development and fourthly to compare its energy efficiency performance with other countries of great importance in world's pulp and paper production, i.e., Canada, Finland, Sweden and the United States of America. As growth of pulp and paper production in these countries is slow it is important for global energy perspective to compare them to a country, Brazil, where the industry is growing fast.

The chosen methodology for this study was the described by [14], the reasons were: (i) it allows the international comparison in physical measures (excluding the distortions caused by the use of monetary measures); (ii) will identify the energy efficiency improvement; (iii) and allows to identify cross-time structural changes within the sector by differing the influences weight of different pulp and paper grades.

This paper is structured in four sections, besides this introduction. Section 1 briefly describes the main energy intensive processes in pulp and paper production. Section 2 shows a detailed description of the characteristics of the Brazilian pulp and paper sector and the changes in its energy consumption 
patterns from 1979 to 2010 . The methodology used in the analysis is described in Section 3, while the results and discussion are in Section 4. Section 5 states the main conclusions of this study.

\section{Pulp and Paper Production}

The World's pulp and paper production in 2010 was approximately 186 and 394 million tonnes, respectively. The world's largest paper and paperboard producers are China, USA, Japan, Germany, Canada, Finland, Republic of Korea, Indonesia, Sweden and Brazil, while the largest pulp producers are USA, China, Canada, Brazil, Sweden, Finland, Japan, Russian Federation, Indonesia and Chile. These countries together were responsible for approximately $81 \%$ and $73 \%$ of 2010 world's pulp and paper \& paperboard production, respectively [30]. Figures 1 and 2 show the development of the annual pulp and paper production of the countries selected for this study.

Figure 1. Annual pulp production of the selected countries.

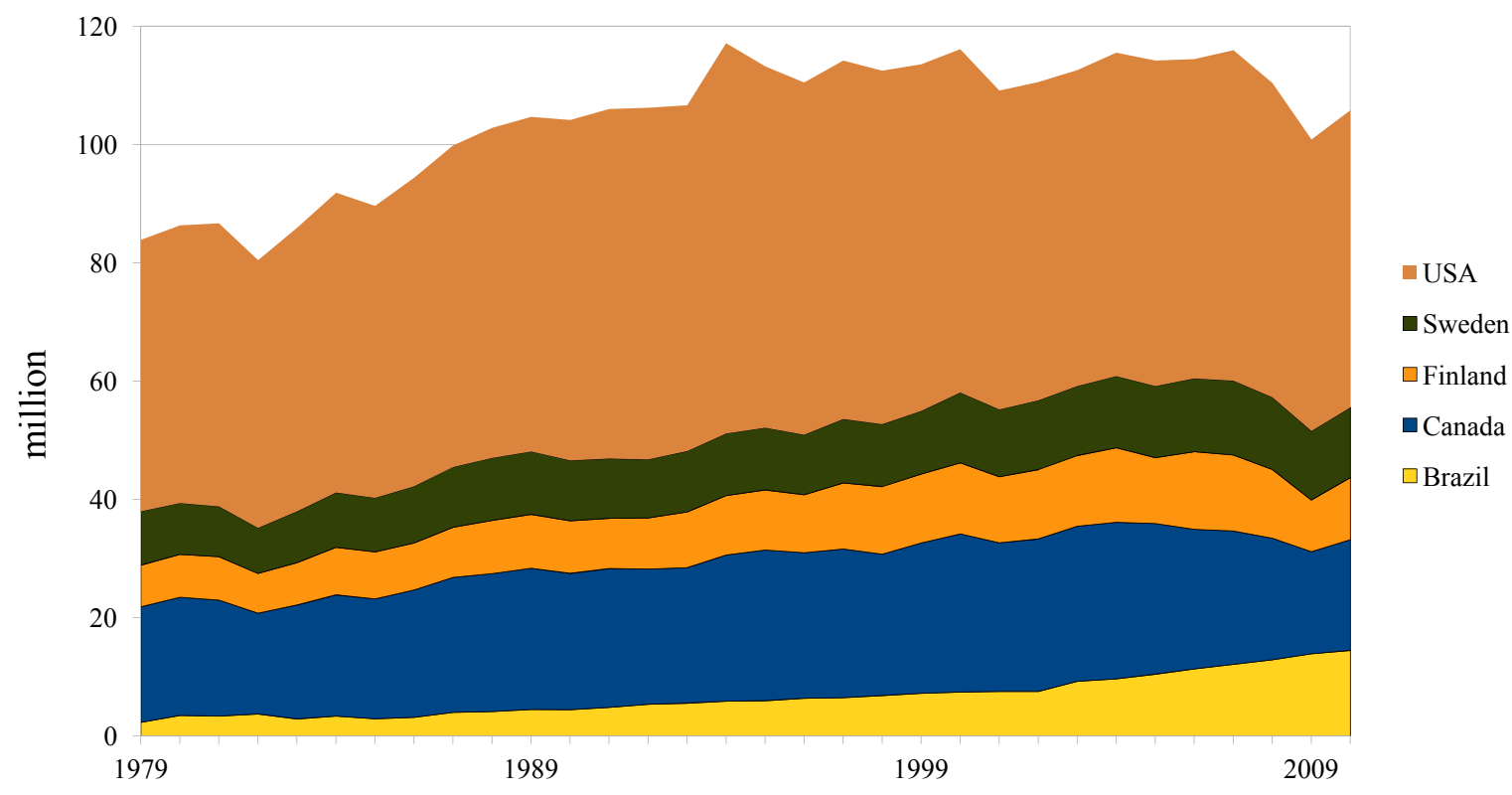

Source: elaborated from [30].

The pulp and paper industry converts fibrous raw materials into pulp, paper and paperboard [17]. Production can happen either in stand-alone pulp mills and stand-alone paper mills or in integrated mills. Pulp types can be produced either through chemical (sulphate or sulphite wood pulp), mechanical (ground or refined wood pulp) or semi-chemical processes (the most common is the Neutral Sulfite Semi-Chemical, NSSC, pulp), and are used as raw material in paper and board production. Recovered paper can also be used as production feedstock [12].

The most significant energy-consuming processes are pulping and drying $[15,17]$ but the specific energy consumption in pulp and paper production is highly influenced by several factors, e.g., product mix (i.e., structure), processes used, plant size, plant location, technology used, technical age of the mill, feedstock quality, fuel prices, utilisation rate of plant capacity, integration level, climate conditions and the level of management attention to energy efficiency $[12,14,15,17]$. 
Figure 2. Annual paper production of the selected countries.

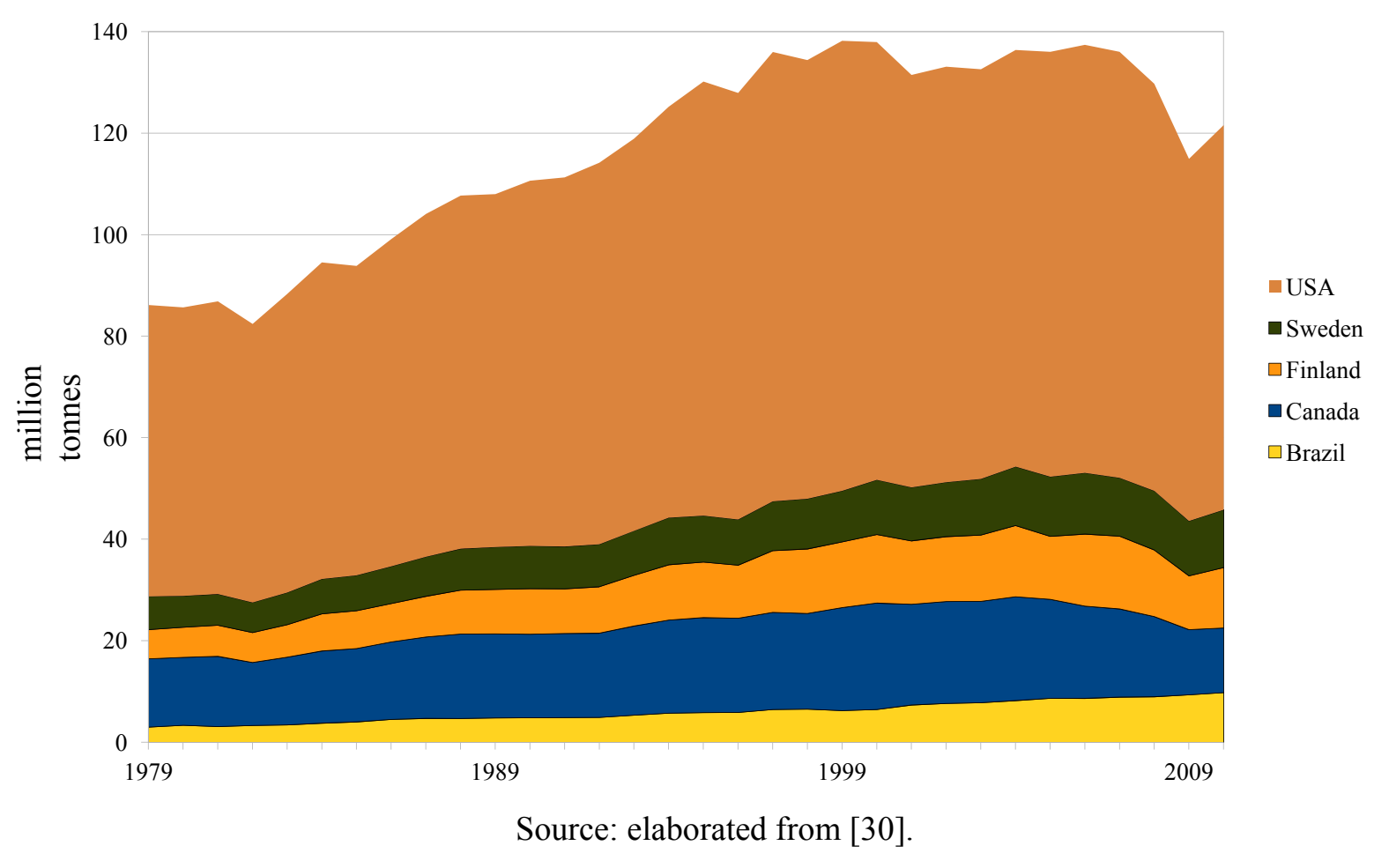

\subsection{The Brazilian Pulp and Paper Industry}

\subsubsection{Production}

Brazil is the world's fourth and the tenth largest pulp and paper producer, respectively [30]. The sector has an important role in Brazilian economy, as it represented $0.3 \%$ and $1.8 \%$ of the country's GDP and industry's value added, respectively [31]. Pulp and paper are the tenth main export products and represented $3.4 \%$ of exported products (in value) in 2010 [32].

From 1979 to 2010 both wood pulp and paper production increased significantly in the country. In 1979 the wood pulp production was around 2.1 million tonnes per year and paper production was approximately 3.0 million tonnes per year, while thirty one years later the annual production of wood pulp and paper was 14.1 and 9.8 million tonnes, respectively. Despite a decrease in wood pulp production between 1982 and 1986, wood pulp and paper production increased at relative similar rates until 2002. In the beginning of the 2000's, propitious worldwide market conditions (e.g., closing of small pulp mills in North America and Europe, increasing acceptability of eucalyptus fibre and rising Chinese pulp demand) led to investments in large capacity chemical pulp mills, Figure 3, increasing the wood pulp production at an annual rate of $8.5 \%$, against $3.1 \%$ in paper production, between 2002 and 2010 [30].

Wood pulp in Brazil is produced mainly through chemical processes, representing $96.7 \%$ of total raw wood pulp produced in the country in 2010, Figure 4. Its production increased at an average annual rate of $6.6 \%$ between 1979 and 2010, when the production reached about 13.6 million tonnes, or $10.2 \%$ of world's wood chemical pulp production. In contrast, the share of mechanical processes has been steadily decreasing since 1985 . In the same period, the mechanical wood pulp production 
increased at an average annual rate of $2.2 \%$, reaching 433,000 tonnes per year in 2010 , which is approximately $1.4 \%$ of world's production [30].

Figure 3. Brazilian pulp and paper annual production.

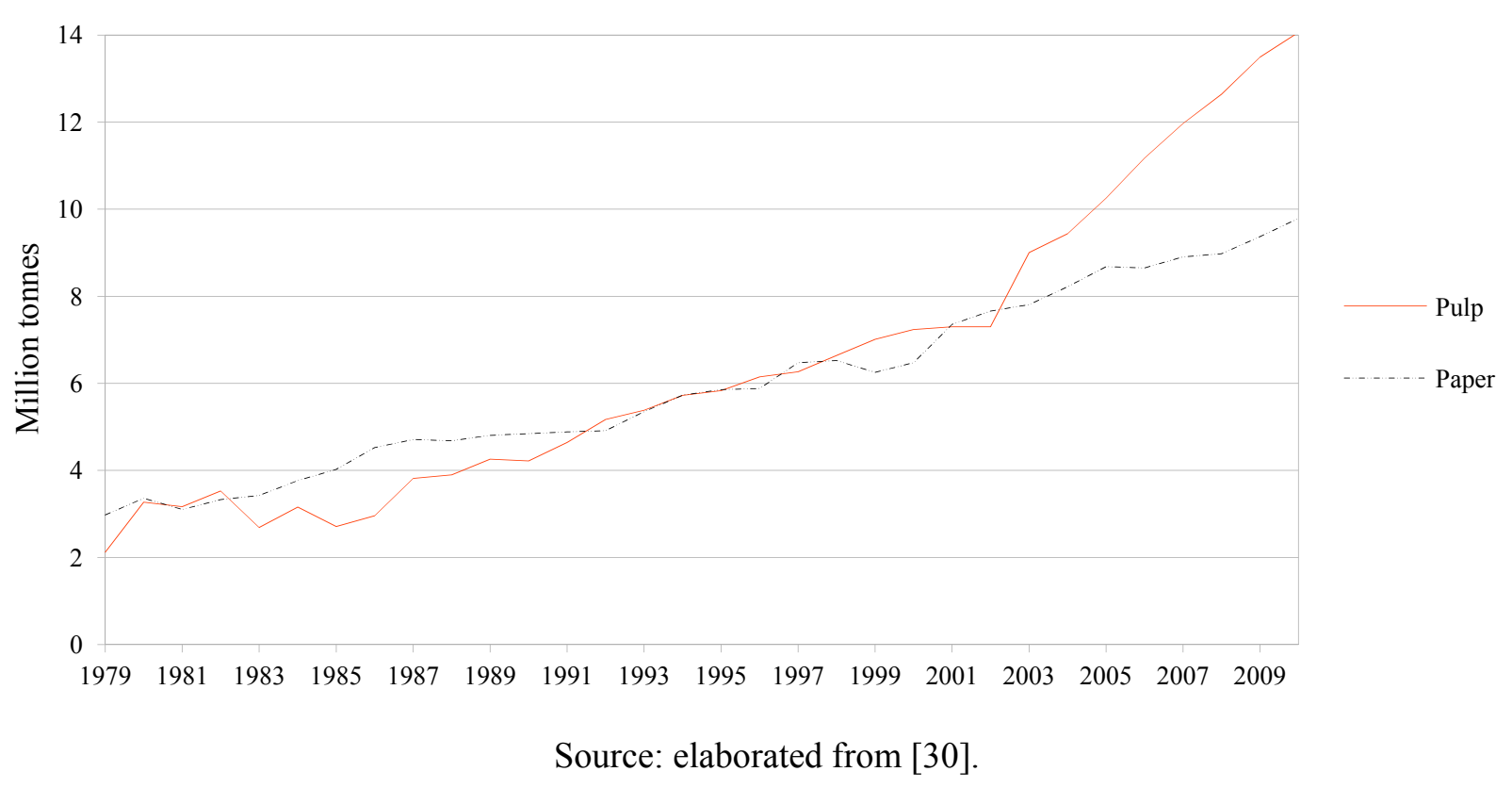

Figure 4. Share of different pulp types in raw wood pulp production in Brazil.

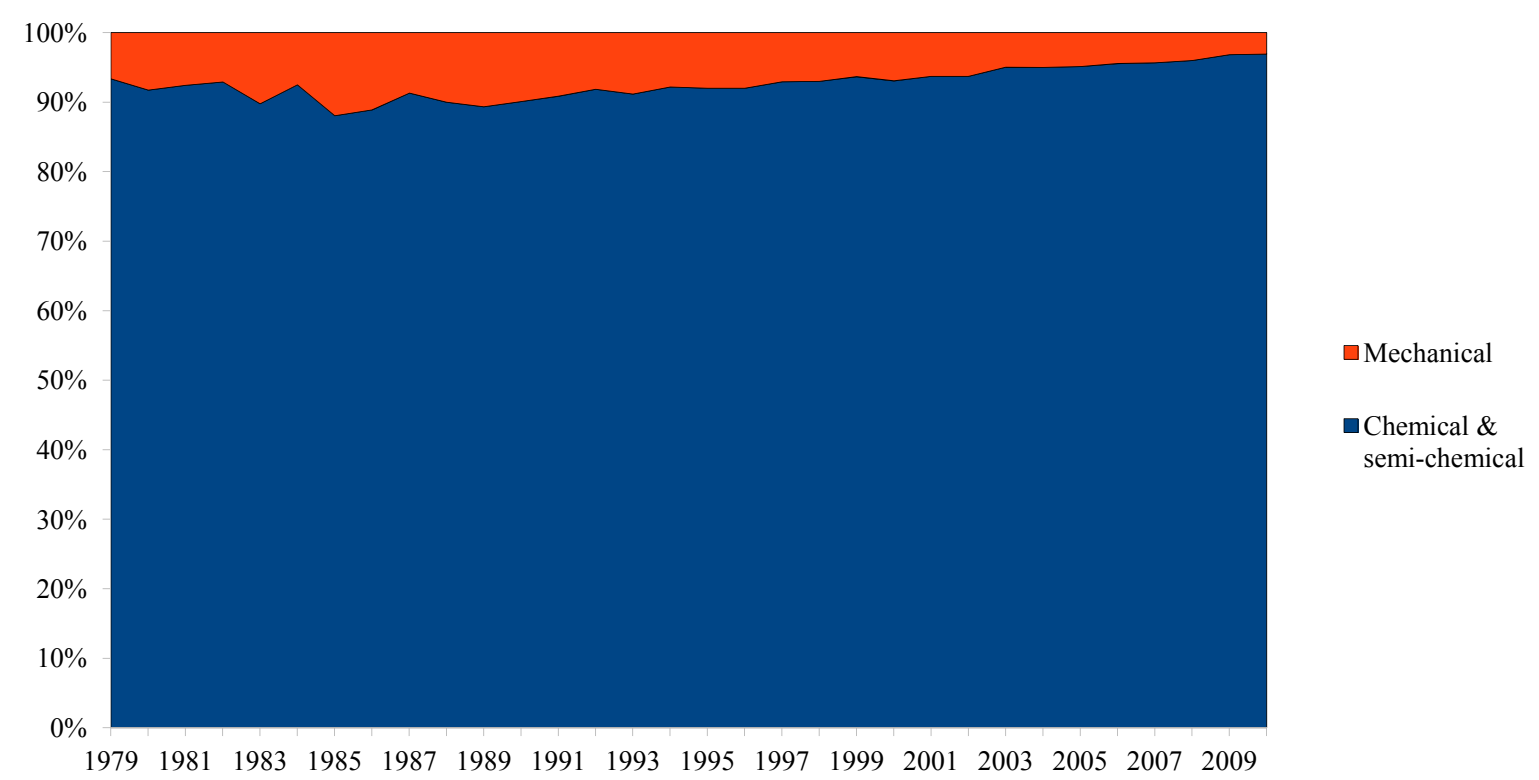

Source: elaborated from [30].

From 1979 to 2010, there were no significant changes in the paper production mix. The share of newsprint production reduced from $3.7 \%$ to $1.3 \%$, which was expected given the reported decrease of mechanical pulp production. On the other hand, household and sanitary paper, printing and writing paper and wrapping and packaging paper and board production increased from $6.8 \%$ to $9.3 \%$, from $25.7 \%$ to $27.6 \%$, and from $47.5 \%$ to $56.2 \%$ [30], respectively, Figure 5. The utilisation of recovered fibre, defined as the ratio between recovered fibre input and total paper production, also increased in 
the analysed period, from 0.8 million tonnes per year in 1979 to 3.9 million tonnes per year in 2010, Figure 6. However, it is expected some inconsistency in the recovered paper data, mainly between 1990 and 1998 when the data is reported at a constant value of approximately 1.3 million tonnes per year.

Figure 5. Share of different grades in Brazilian paper and board production.

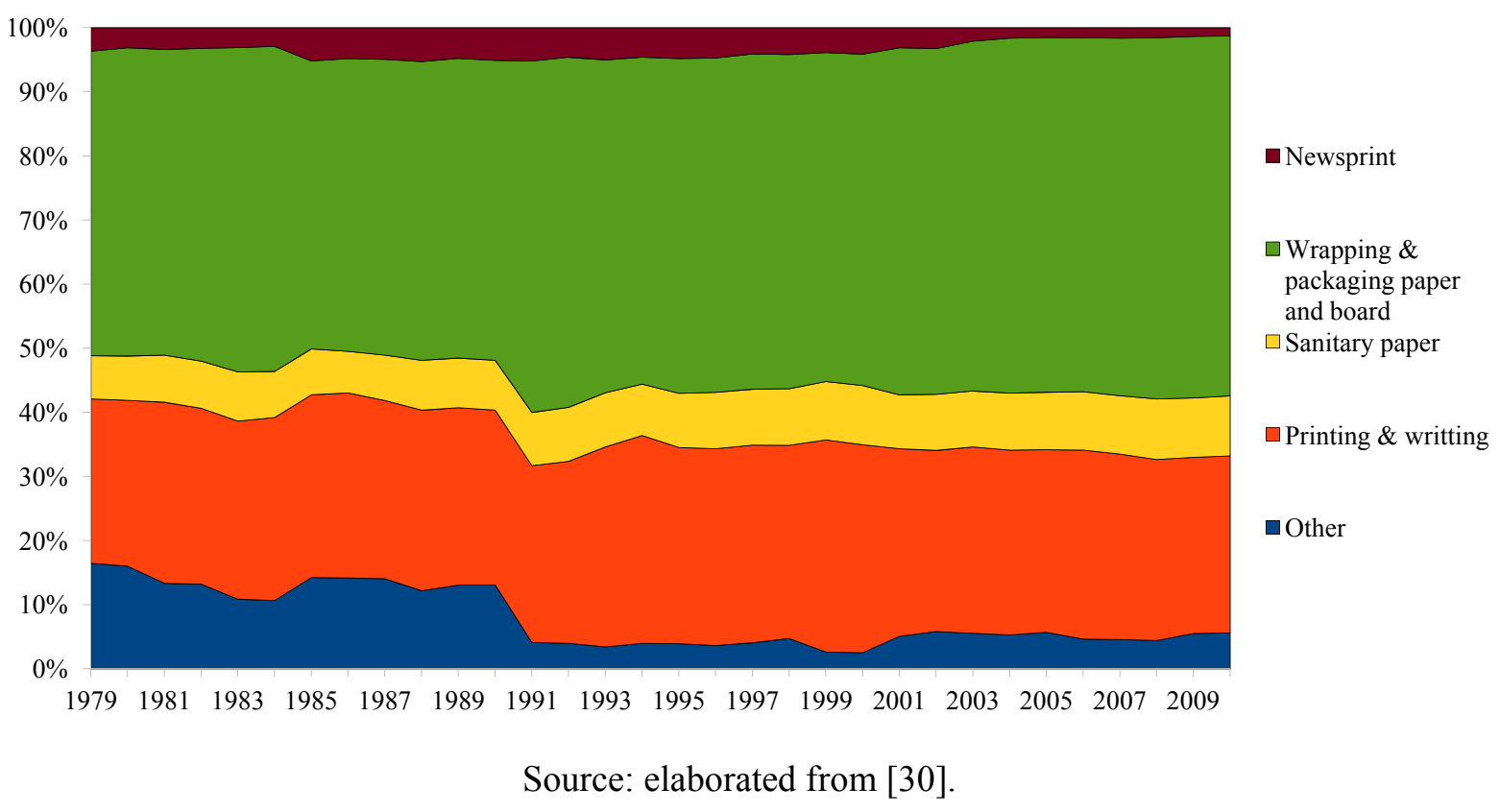

Figure 6. Recycled fibre utilization rate in Brazil.

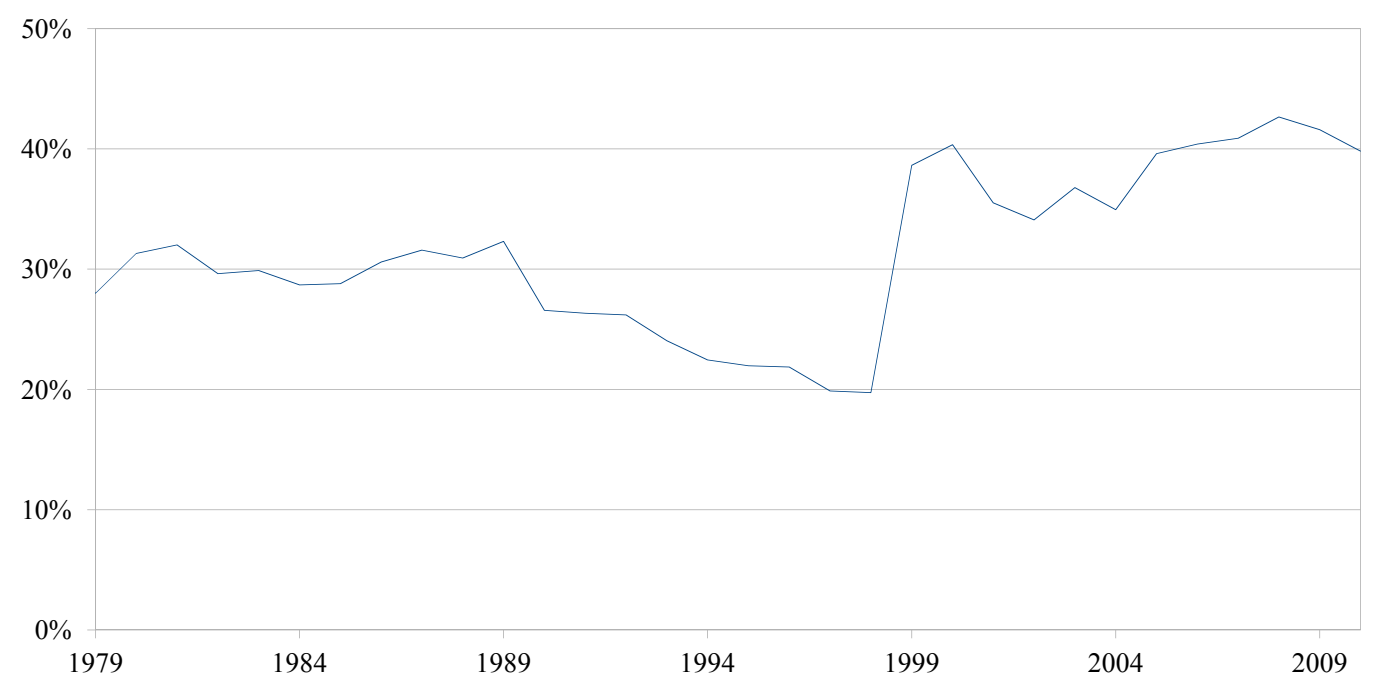

Source: elaborated from [30]. 


\subsubsection{Energy Consumption}

Industry represents approximately $38 \%$ of final energy consumption in Brazil. The share of pulp and paper sector increased from $6.8 \%$ in 1979 to $11.8 \%$ in 2010 of industry's final energy consumption, and from $2.4 \%$ to $4.5 \%$ of the total final energy consumed in the country. Figure 7 shows the total final energy consumption and the share of both industrial and pulp and paper sectors from 1979 to 2010 and Figure 8 shows the yearly energy consumption of pulp and paper sector in terms of final energy (i.e., electricity and fuels). During the analysed period, electricity consumption of pulp and paper sector increased from 16.0 PJ in 1979 to $69.3 \mathrm{PJ}$ in 2010, while fuels consumption increased from 83.8 PJ in 1979 to $352.6 \mathrm{PJ}$ in 2010. One important characteristic of the sector is its share of self-generated electricity, which was 40\% in 1994 (i.e., 14 PJ) and increased up to 51\% in 2010 (i.e., $35 \mathrm{PJ})$, with $1.74 \mathrm{GW}$ of installed capacity $[31,33,34]$.

Figure 7. Final energy consumption in Brazilian industrial sector.

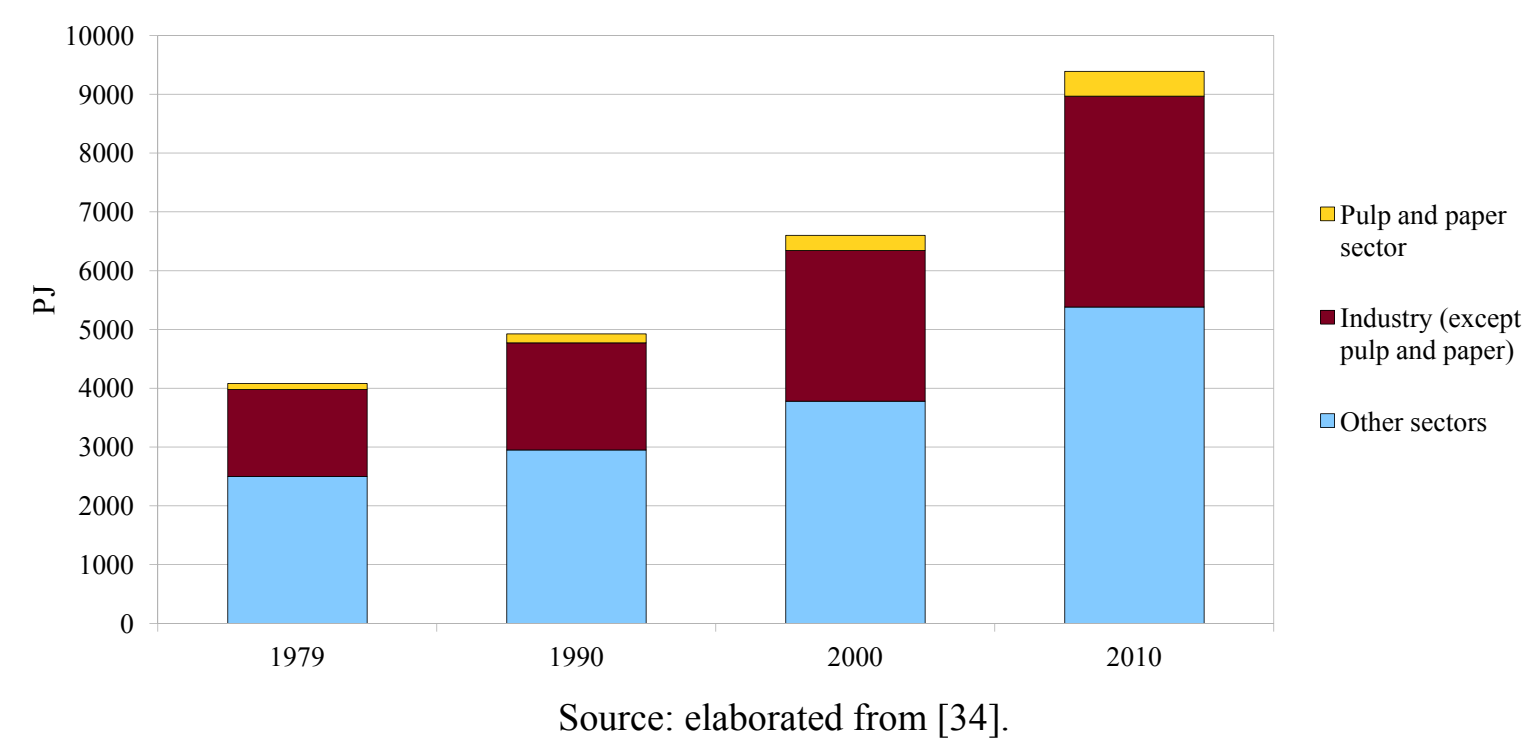

Figure 8. Energy consumption in Brazilian pulp and paper sector.

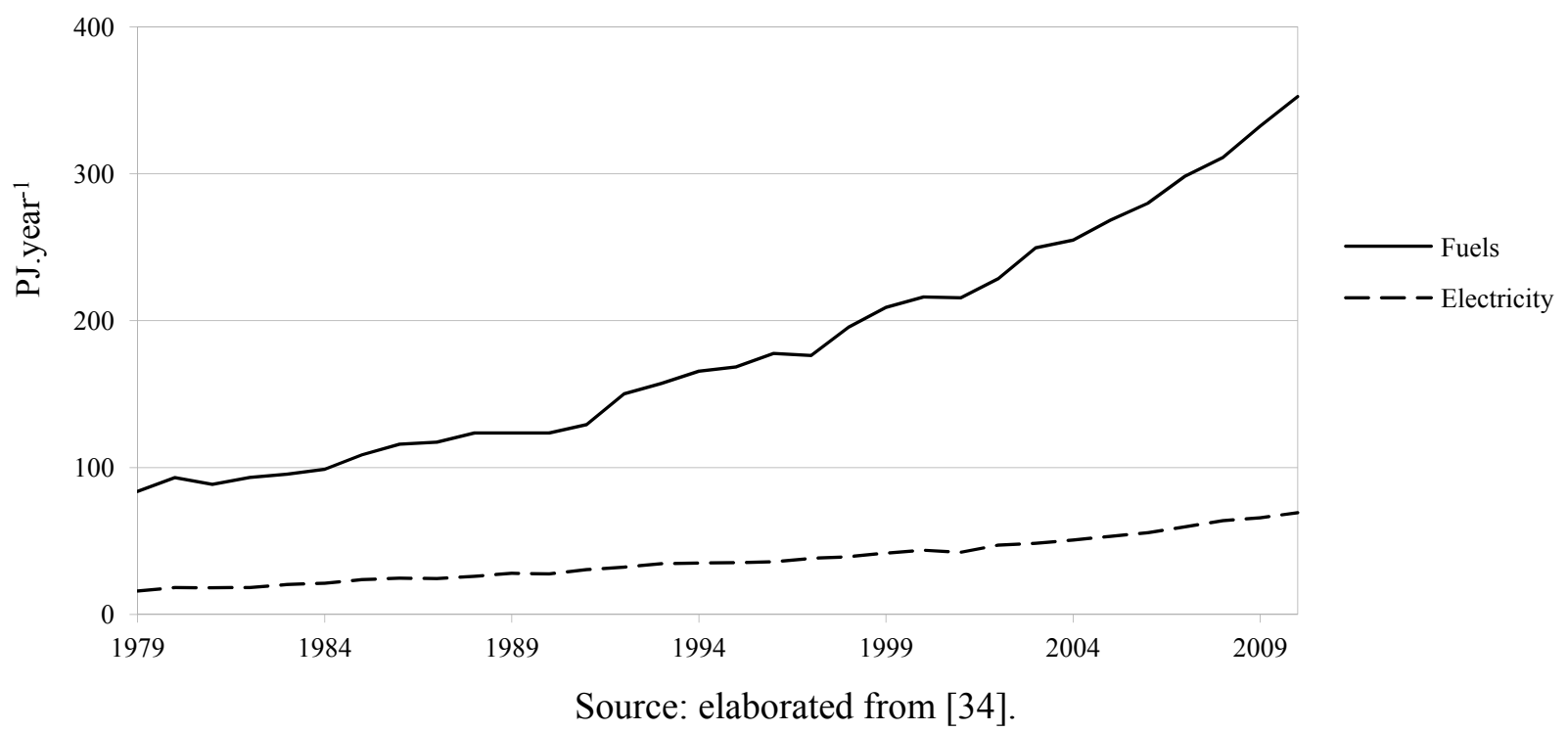


Figure 9 shows the shares of both renewable and fossil fuels used by the sector since 1979, according to the official Brazilian energy balance. In the fossil fuels category are included natural gas, coal, diesel oil, heavy oil, liquefied petroleum gas, petroleum coke, kerosene, and other not specified. Renewable fuels are related to wood, sugar cane bagasse, black liquor and other wastes.

Figure 9. Share of fossil and renewable fuels consumed by Brazilian pulp and paper sector.

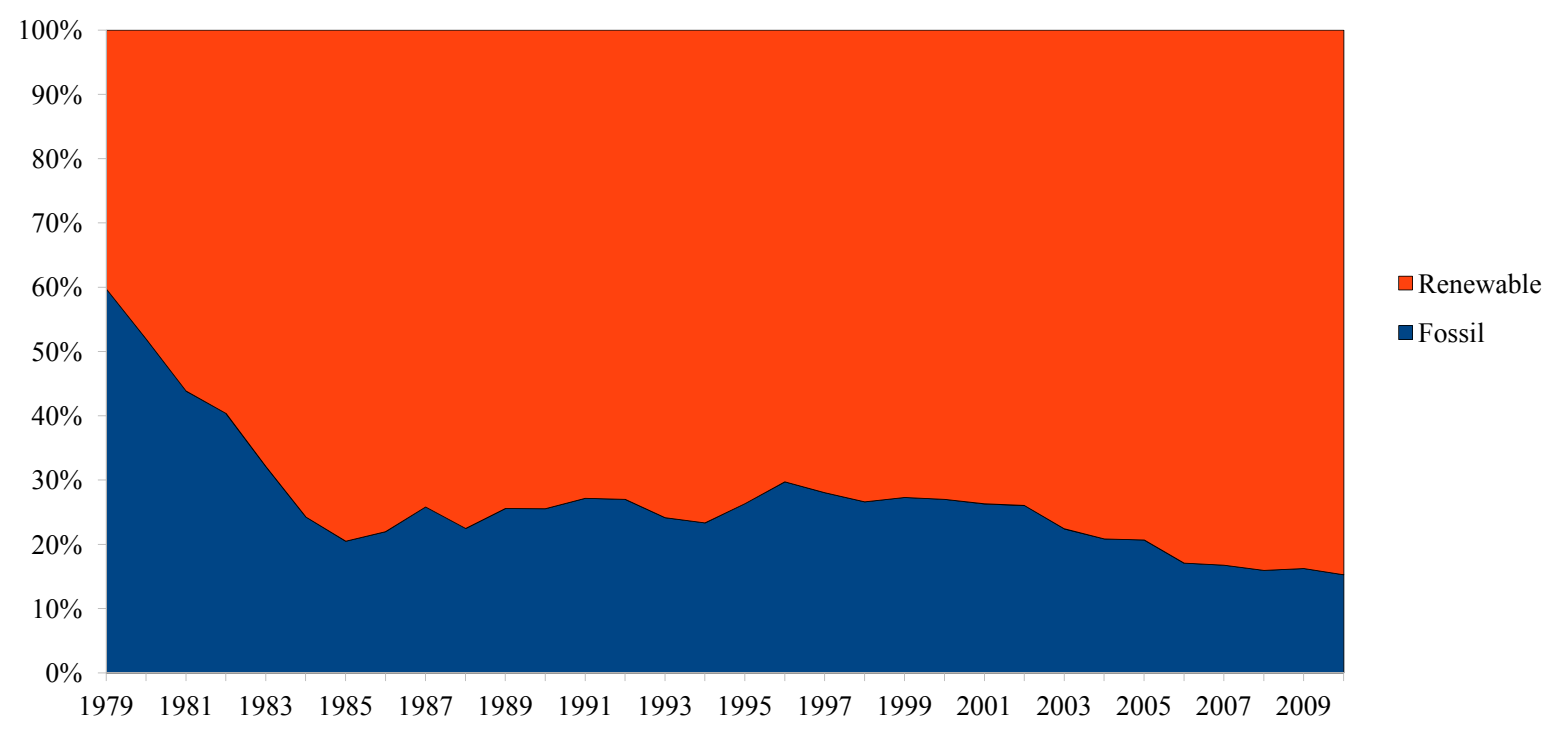

Source: elaborated from [34].

An important change in fuel mix happened between 1979 and 1985 when, due to rising oil prices, the Brazilian government implemented a programme in cooperation with the Brazilian Association of Pulp and Paper (BRACELPA) intending to replace the use of foreign oil-derived fuels in industry [35]. During this programme there was a significant replacement of heavy oil by wood and since then the sector remained using a high share of renewable fuels.

Figure 10. Share of different fuels consumed by Brazilian pulp and paper sector.

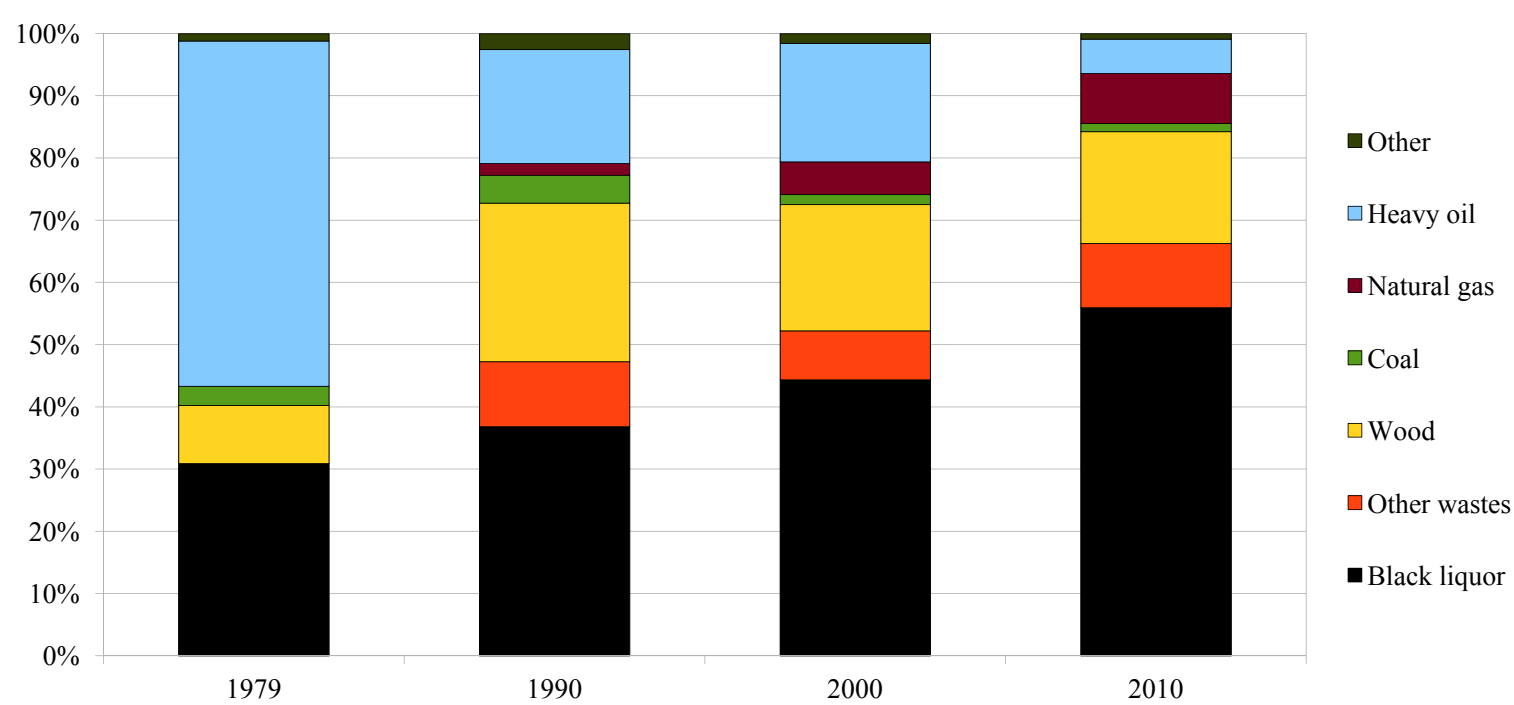

Source: elaborated from [34]. 
The share of the main fuels used in pulp and paper sector is shown in Figure 10. Black liquor was the main fuel used in 2010, with a share of 55.9\%, in 1979 the share of this fuel was $30.9 \%$. Its importance as the main fuel consumed in the pulp and paper sector can be explained by the high share of chemical processes in Brazilian wood pulp production and its significant growth in the considered period. Wood $(18.0 \%)$, other wastes $(10.3 \%)$, natural gas $(8.0 \%)$, and heavy oil $(5.5 \%)$ were the other main fuels consumed by the sector in 2010 . Besides being significantly replaced by wood in the first half of the 1980's heavy oil also lost importance during the 1990's mainly because of the increasing share of natural gas, which was introduced in the industry by the end of the 1980's.

\section{Energy Efficiency Development}

In this work we used the methodology presented by [14], which allows a comparison of the influences of the three parameters (activity level, sector structure and energy efficiency) in the energy consumption development of the pulp and paper sector in the selected countries. The analysis refers to a 30 years period, i.e., from 1979 to 2009 , and methodology is described in the following sections.

\subsection{Physical Production Index}

According to Farla et al., 1997, the total energy consumption of a sector can be written as follows:

$$
\sum E=\sum P \cdot\left(P P I / \sum P\right) \cdot\left(\sum E / P P I\right)[0,1]
$$

where $\sum E$ is the total energy consumption, $\sum P$ is the total production and $P P I$ is the physical production index of the sector. This equation means that the total energy consumption of a given sector is determined by its production activity $\left(\sum P\right)$, production mix $\left(P P I / \sum P\right)$ and energy efficiency $\left(\sum E / P P I\right)$. While the total production is just a sum of the production outputs of the sector, the $P P I$ is determined by the following equation:

$$
P P I=\sum_{x=1}^{n}\left(P_{x} \cdot w_{x}\right)
$$

where $P$ is the production of a product $\mathrm{x}$ and $\mathrm{w}$ is the weighting factor, which is the specific energy required to produce the product $\times$ based on the best available technique. The specific energy consumption values considered are listed in Table 1.

Table 1. Weighting factors for pulp and paper production.

\begin{tabular}{ccc}
\hline & Heat $\left(\mathbf{G J}_{\mathbf{h}} / \mathbf{t}\right)$ & Electricity $\left(\mathbf{G J} \mathbf{J}_{\mathbf{e}} / \mathbf{t}\right)$ \\
\hline Mechanical pulping & -2.1 & 5.3 \\
Chemical pulping & 10.0 & 2.5 \\
Other pulps & -3.0 & 6.0 \\
Recycled fibre input & 0.4 & 1.4 \\
Household \& Sanitary paper & 5.0 & 2.4 \\
Newsprint & 2.5 & 1.4 \\
Printing \& writing paper & 7.0 & 2.0 \\
Wrapping \& packaging paper and board & 5.0 & 1.5 \\
Other papers & 6.0 & 1.8 \\
\hline
\end{tabular}

Source: adapted from [14]. 
The ratio between the $P P I$ and the energy consumption in a given year results in the Energy Efficiency Index (EEI). The EEI shows the energy saving potential that could be reached in the analysed year if the whole sector had produced all its products with the best available techniques, which would result in a EEI equal to $100 \%$.

For the Brazilian pulp and paper sector, the energy efficiency development analysis is separated in the electricity, heat and primary energy developments. The fuel-to-heat efficiency considered is $80 \%$, so the values of the heat required in the BAT's specific energy consumption are divided by this factor. The primary energy consumption is determined by the sum of the electricity consumption, divided by an efficiency conversion factor of $40 \%$, and the fuel consumption. The use of primary energy for the international comparisons is justified by an attempt of reducing potential distortions that can happen when considering on site electricity generation [36].

\subsection{Decomposition Analysis}

Reference [14] adopted the method of additive energy consumption technique and used the simple average parametric Divisia method 2, which is, amongst several others, described by [37]. The choice of this method was based on "obtaining a small residual term and the ease of implementation". Aiming to obtain a smaller residual term the analysis was performed on a rolling base year (i.e., changes were calculated from year to year and then summed over the analysed period). The index decomposition approach is performed as follows:

$$
\sum E=\Delta E_{p d n}+\Delta E_{s t r}+\Delta E_{i n t}+\Delta E_{r s d}
$$

where $\Delta E_{\text {pnd }}$ refers to the changes related to the production activity, $\Delta E_{\text {str }}$ to the production mix, $\Delta E_{\text {int }}$ to the energy efficiency and $\Delta E_{r s d}$ is the residual term. These terms are calculated by the following equations:

$$
\begin{gathered}
\Delta E_{p d n}=\left[I_{0}+\alpha\left(I_{T}-I_{0}\right)\right]\left(Y_{T}-Y_{0}\right) \\
\Delta E_{s t r}=\sum\left[I_{i, 0} Y_{0}+\beta_{i}\left(I_{i, T} Y_{T}-I_{0} Y_{0}\right)\right]\left(S_{i, T}-S_{i, 0}\right) \\
\Delta E_{\text {int }}=\sum\left[Y_{i, 0}+\tau_{i}\left(Y_{i, T}-Y_{i, 0}\right)\right]\left(I_{i, T}-I_{i, 0}\right)
\end{gathered}
$$

Being $Y$ the production output of the sector and $Y_{i}$ the production output of product " $i$ ", $I(=E / Y)$ the energy intensity of the sector and $I_{\mathrm{i}}\left(=E_{i} / Y_{i}\right)$ the energy intensity of product " $i$ " and $S_{i}\left(=Y_{i} / Y\right)$ the production share of product " $i$ ". The terms " $T$ " and " 0 " refer to analysed years, in a rolling base year analysis $(T=0+1)$ and the parameters $\alpha, \beta i$ and $\tau i$ are calculated by the following equations:

$$
\begin{gathered}
\alpha=\left[I_{0}\left(Y_{T}-Y_{0}\right)-E_{0} \ln \left(Y_{T} / Y_{0}\right)\right] /\left[\left(I_{0}-I_{T}\right)\left(Y_{T}-Y_{0}\right)-\left(E_{0}-E_{T}\right) \ln \left(Y_{T} / Y_{0}\right)\right] \\
\beta_{i}=\left[I_{i, 0} Y_{0}\left(S_{i, T}-S_{i, 0}\right)-E_{i, 0} \ln \left(S_{i, T} / S_{i, 0}\right)\right] /\left[\left(I_{i, 0} Y_{0}-I_{i, T} Y_{T}\right)\left(S_{i, T}-S_{i, 0}\right)-\left(E_{i, 0}-E_{i, T}\right) \ln \left(S_{i, T} / S_{i, 0}\right)\right] \\
\tau_{i}=\left[Y_{i, 0}\left(I_{i, T}-I_{i, 0}\right)-E_{i, 0} \ln \left(I_{i, T} / I_{i, 0}\right)\right] /\left[\left(Y_{i, 0}-Y_{i, T}\right)\left(I_{i, T}-I_{i, 0}\right)-\left(E_{i, 0}-E_{i, T}\right) \ln \left(I_{i, T} / I_{i, 0}\right)\right]
\end{gathered}
$$




\subsection{Data Gathering}

Despite the known usefulness of physical-thermodynamic energy efficiency indicators, a low quality in terms of comprehensiveness, consistency and validation of the data required can limit the depth and validity of the analysis [9]. For international comparisons there are important issues that must be taken into consideration before using these indicators, mainly if they are based on national databases. The main potential problems found in the literature are related to the quality of energy consumption data, and the different definitions regarding the system boundaries, the type of energy reported, the classification of self-generated electricity, the heat content of the fuels, the non-energetic use of fuels, the classification of the fuels and the use of unconventional energy sources [3,36,38,39]. In addition differences caused by the average outside air and raw water temperature, wood species used and other local conditions will cause additional minor differences in energy use.

Data problems regarding the use of physical energy efficiency indicators were studied by [36]. They compared energy consumption data of the iron and steel industry from four international sources, IEA, IES, Eurostat and IISI. Their analysis found that the accuracy of the indicators is mainly determined by the accuracy of the energy consumption data used, while both the production data and the specific energy consumption values used were less problematic. Some reporting mistakes were found, e.g., double counting and non-reporting of energy carriers, in both Eurostat and IEA database. They concluded that international sources of energy consumption data do not guarantee that the data for different countries are comparable to each other, so the consistency of the data must be checked.

\subsubsection{Production}

The pulp and paper production data of the selected countries was gathered from FAO Forestry database. We found some potential inconsistencies, e.g., the same value reported for "recovered paper" in Brazil from 1990 to 1998, followed by a sudden increase. The Brazilian Association of Pulp and Paper (BRACELPA) provides an annual statistical report with information about the sector within the country, e.g., pulp and paper production, but this information is only available since 1990. By comparing the FAO and BRACELPA data some punctual differences were found, the highest difference is in the 1998 and 1999 paper production, when BRACELPA data is around 11\% higher, in the other years the differences were not significant. In pulp production BRACELPA shows a value $10 \%$ higher than FAO for the year 2002. As these differences are also expected to happen in the production data of the selected countries, we decided to use the FAO data in the analysis.

\subsubsection{Energy Consumption}

The energy consumption data of the Brazilian pulp and paper industry was obtained from the National Energy Balance [34]. The data referred to the energy consumption of the countries evolved in the international comparison (i.e., Canada, Finland, Sweden and USA) was gathered from the International Energy Studies group (IES) of the Lawrence Berkeley National Laboratory (LBNL) [40] and from the International Energy Agency (IEA) [40-49]. The IES data refers to the period between 1979 and 1991, the IEA data was used for the 1992-2009 period. The utilisation of two different international database was due the unavailability of continuous data over the analysed period (the IES 
energy consumption data referred to the Canadian pulp and paper industry is available until 1987, so the IEA data was used in the 1988-2009 period. Due to inconsistencies in the Finnish and American energy consumption data referred to the period between 1992 and 1999, the energy efficiency indexes of these countries were not considered). The printing industry is not included in the Brazilian energy consumption data. Because of this, both the IEA and IES data were reduced by $5 \%$, which was the estimated share of the printing industry energy consumption.

\section{Results and Discussion}

The first part of this section shows the decomposition analysis of the energy consumption of Brazilian pulp and paper sector, showing the influence of the activity intensity, product mix and energy efficiency in the developments of electricity, heat and primary energy consumption, from 1979 to 2009. Further, the energy efficiency indexes developments are presented, followed by explanatory factors aiming to point some causes to the changes in the energy consumption patterns. The fourth part of this section is dedicated to the international comparison of the energy efficiency indexes developments of the selected countries.

Figure 11. Influence of activity, structure and efficiency in the energy consumption development of Brazilian pulp and paper sector during 1979-2009.

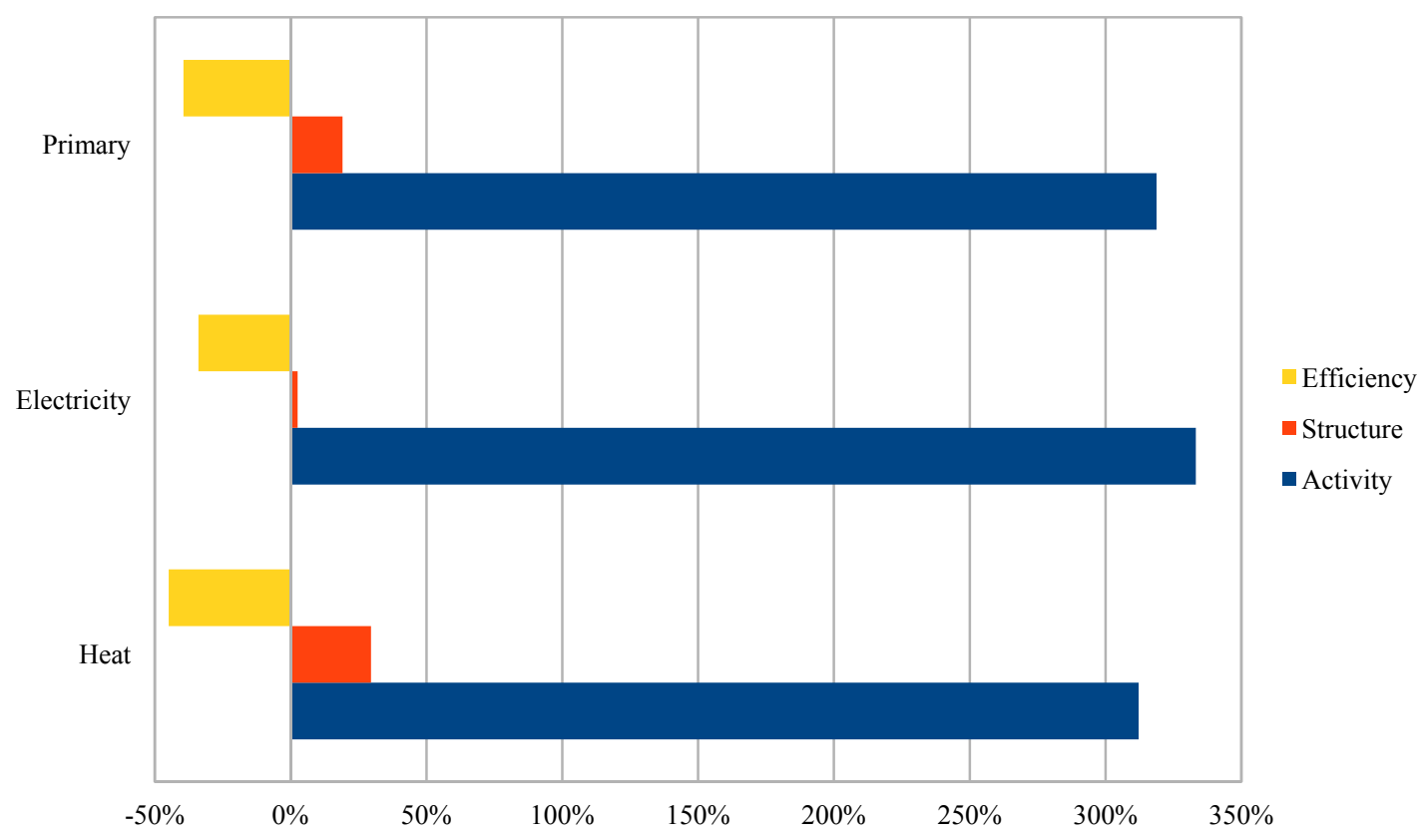

As illustrated by Figure 11, the energy consumption increase of Brazilian pulp and paper industry over the analysed period was mainly due the significant growth of pulp and paper production. Between 1979 and 2009, the rising activity level influenced increases of 398.0 PJ (321\% of the energy consumption in 1979), 263.3 PJ (314\%) and 53.8 PJ (335\%) in the consumption of primary energy, fuels and electricity, respectively. The pulp production growth was approximately $503 \%$, from 3.1 to 17.8 million tonnes, and the paper production grew $215 \%$, from 3.0 to 9.4 million tonnes. In the same period, the primary energy consumption was $299 \%$ higher (from 124.0 to $494.1 \mathrm{PJ}$ ), while the fuel and 
electricity consumption growth was approximately $297 \%$ (from 83.8 to 332.4 PJ) and $302 \%$ (from 16.1 to $64.7 \mathrm{PJ})$, respectively.

The structural changes of the Brazilian sector were responsible for increases of 24.8 PJ (30\%) and 23.7 PJ (19\%) in fuels and primary energy consumption, respectively. However, the influence of these changes in the electricity consumption was much smaller, being responsible for a 0.4 PJ reduction $(3 \%)$.

The most important structural changes in Brazilian pulp production were a larger share of chemical pulp, rising from $85.7 \%$ of the total pulp production in 1979 to $93.9 \%$ in 2009 and the smaller share of mechanical pulp, reducing from $6.1 \%$ to $3.1 \%$ in the same period. In paper production, the main structural changes were the larger share of the wrapping and packaging paper and board, from $47.5 \%$ to $56.4 \%$, and the reduction of the other papers category, from $16.4 \%$ to $5.5 \%$. Another significant change refers to the rising recovery fibre utilisation rate, from $28.0 \%$ in 1979 to $41.6 \%$ in 2009 [30].

Higher efficiency levels also had great influence in the energy consumption changes of Brazilian sector. This factor influenced a $51.0 \mathrm{PJ}(41 \%)$ reduction in the primary energy consumption over the 30 years period. The influences in fuels and electricity consumption were, respectively, 38.9 PJ (46\%) and $5.6 \mathrm{PJ}(35 \%)$.

Figure 12. Energy efficiency indexes for primary energy, fuels and electricity consumption in Brazilian pulp and paper sector during 1979-2009.

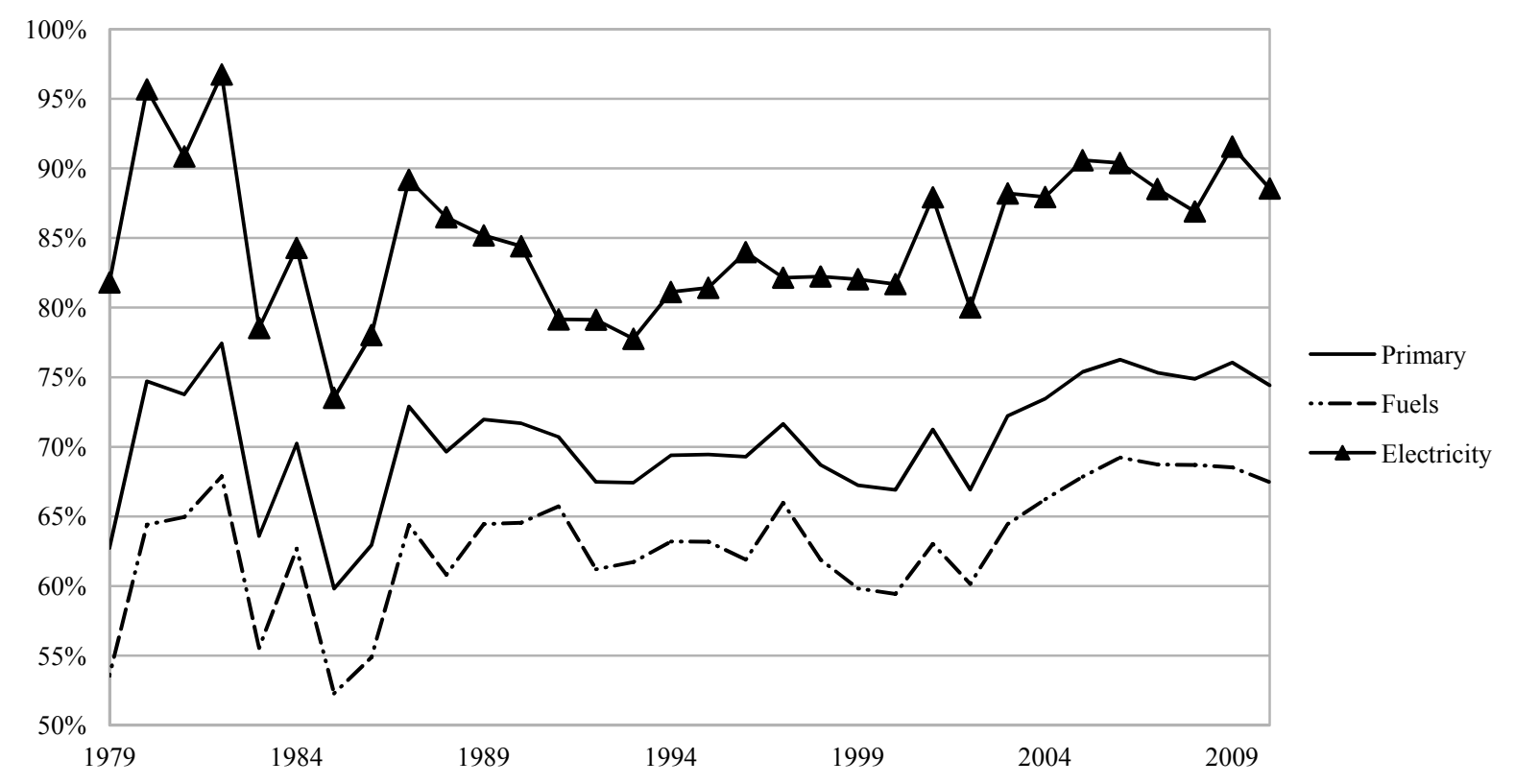

The developments of the energy efficiency levels of Brazilian pulp and paper industry, demonstrated by the energy efficiency indexes (EEI's), are shown by Figure 12. The graphic shows that the electricity consumption is historically more efficient than fuels consumption. However, as argued by [14], this difference may be overestimated because of a possible use of fuels to run equipment in pulp and paper mills in the past.

As illustrated in Figure 12, all the three energy efficiency indexes showed sharp variations between 1979 and 1987. From 1988 to 1999 the energy efficiency levels maintained relatively stable, except for 
the reduction in the efficiency of electricity consumption until 1991. During the 2000's, mainly in its first half, rising energy efficiency levels can be visualised. From 2000 to 2009, the primary energy efficiency index grew from $67 \%$ to $76 \%$, while the indexes referred to the fuels and electricity consumptions rose, respectively, from $59 \%$ to $69 \%$, and from $82 \%$ to $92 \%$, in the same period. These increases were influenced by two main factors, i.e., rising energy prices and the installation of very large pulp mills, which are explained further.

\subsection{Explanatory Factors}

\subsubsection{Energy Prices}

Figure 13 shows the variations in the prices of energy inputs (i.e., electricity, natural gas, coal, and heavy oil) between 1979 and 2010. The prices related to 1994 showed an abrupt variation in all energy inputs and were not considered in the following discussion.

Figure 13. Energy prices in Brazil from 1979 to 2009.

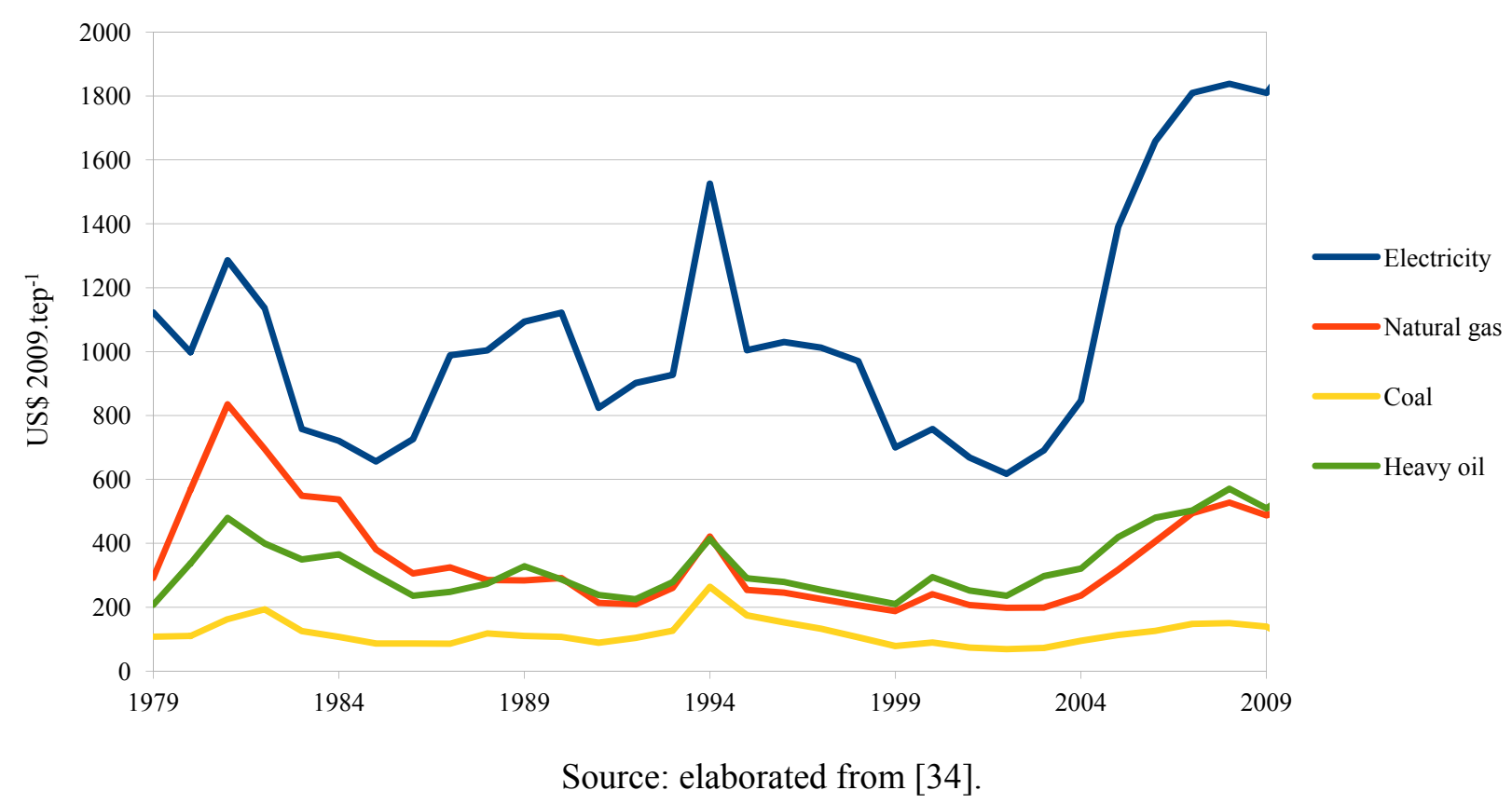

Although some characteristics of the Brazilian sector (i.e., a high rate of self-generated electricity, of $51 \%$ in 2010 , and the high share of chemical pulp in the overall production) harm a deeper analysis of the impacts of energy prices variations in the efficiency levels, there are two periods in which the energy prices showed some influence in the EEI's. From 1981 to 1985, there were an overall reduction in energy prices, the average electricity price for industry reduced approximately $49 \%$, heavy oil price $38 \%$ and coal $47 \%$ (natural gas consumption was not significant in early 1980s). During this period, the energy efficiency indexes related to fuels and electricity consumption reduced approximately $19 \%$. Between 2002 and 2008 there were significant increases in energy prices. The electricity price rose approximately 198\%, while the heavy oil, natural gas, and coal increased, respectively, $142 \%, 166 \%$, and $118 \%$. During these years the efficiency of electricity consumption increased $9 \%$ and the efficiency of fuels consumption was $14 \%$ higher. 


\subsubsection{Installed Capacity}

The average size of Brazilian chemical pulp mills have been increasing during time, in 1993 the average installed capacity was approximately 138,600 tonnes of pulp per year, rising up to 500,340 tonnes/year. Figure 14 shows the share of chemical pulp mills, by range of installed capacity, in total installed capacity. In 1993 there was no chemical pulp mill with an installed capacity higher than 1 million tonnes per year, while in 2009 these mills had a share of $56.1 \%$ in total installed capacity [50]. The most significant change occurred between 2001 and 2007, when the share of mills with a production capacity higher than 1 million tonnes per year increased from $17.0 \%$ to $57.3 \%$. There is no available data regarding changes in installed capacity of individual paper mills.

Figure 14. Share of different ranges of installed capacity in the total installed capacity of Brazilian chemical pulp between 1993 and 2009.

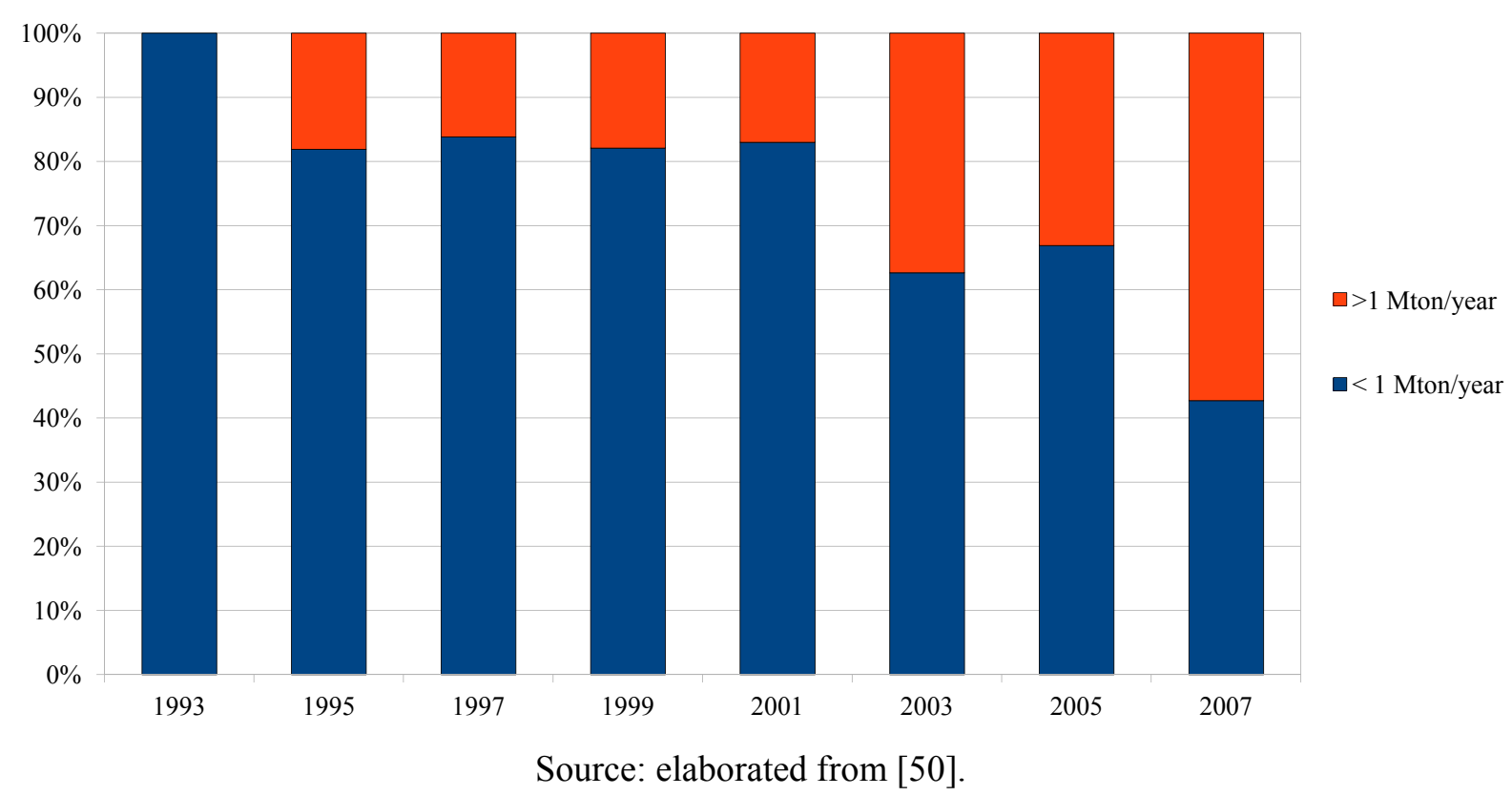

\subsection{International Comparison}

\subsubsection{Energy Efficiency Indexes}

The great instability of the Brazilian energy efficiency indexes between 1979 and 1987, visualized in Figure 12, can be explained by a possible asynchrony between the production and energy consumption data. Aiming to reduce the impact of this possible asynchrony, the international comparison was based on 3-years average energy efficiency indexes $\left(\mathrm{EEI}_{3}\right.$; the $\mathrm{EEI}_{3}$ of a given year is built using the average values of both physical production and energy consumption of the given year and the two years before it).

Figure 15 shows the developments of the $\mathrm{EEI}_{3}$ 's of the pulp and paper sector of Brazil, Canada, Finland, Sweden, and USA, from 1979 to 2009. The graphic shows that in 1979 the most energy efficient industry was the Finnish (with an $\mathrm{EEI}_{3}$ of $80 \%$ ), followed by the Swedish (71\%), the Canadian (66\%), the Brazilian (75\%), and the American (57\%) industries. In 2009, both the Finnish 
and Swedish industries were the most energy efficient amongst the analysed, with an $\mathrm{EEI}_{3}$ of $89 \%$, followed by the Brazilian (75\%), the American (73\%) and the Canadian (62\%), being the latter the only one where there was a decrease in the energy efficiency level.

Figure 15. Energy efficiency indexes-years average.

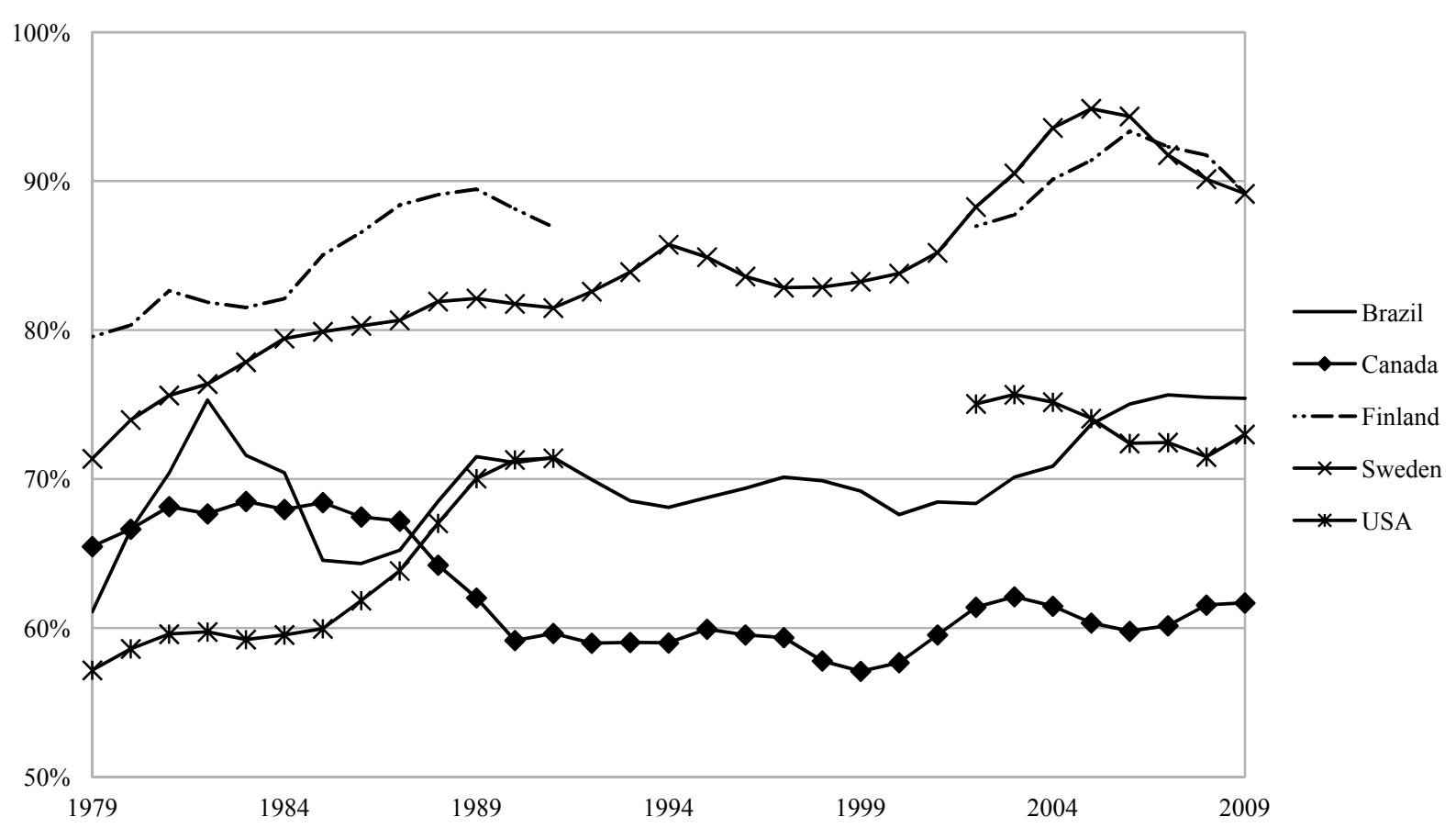

Considering that industrial energy efficiency levels are typically assumed to increase at an annual "normal rate" of $1 \%[1,6]$, the energy efficiency increases found in this analysis were significantly lower. The annual energy efficiency increase of the American industry was approximately $0.79 \%$ between 1979 and 2009. The Swedish, the Brazilian and the Finnish industries increased their energy efficiency levels at a rate of $0.71 \%, 0.67 \%$ and $0.37 \%$ per year, respectively, while the Canadian industry decreased its energy efficiency consumption at an annual rate of $0.19 \%$ mainly due to developments prior to 1990 .

The 3-years average energy efficiency indexes showed 1229.0 PJ of potential primary energy savings amongst the analysed countries in 2009. In absolute terms, the biggest potential is in the American industry, with 742.7 PJ. The Canadian industry has a 290.5 PJ potential, followed by the Brazilian (115.7 PJ), the Finnish (40.8 PJ) and the Swedish (39.3 PJ).

\subsubsection{Decomposition Analysis}

The decomposition of the primary energy consumptions are shown in Figure 16. From 1979 to 2009, the primary energy consumption of the Brazilian, Finnish, Swedish and Canadian industries increased, respectively, 299\% (from 124.0 to $494.1 \mathrm{PJ}$ ), 40\% (from 216.3 to $303.7 \mathrm{PJ}$ ), 19\% (from 294.5 to $350.0 \mathrm{PJ}$ ) and 5\% (from 628.9 to $661.5 \mathrm{PJ}$ ). Only in the USA the primary energy consumption decreased between 1979 and 2009, approximately 2\% (from 2,542.4 to 2,489.3 PJ). 
Figure 16. Influence of activity, structure and efficiency in primary energy consumption development from 1979 to 2009.

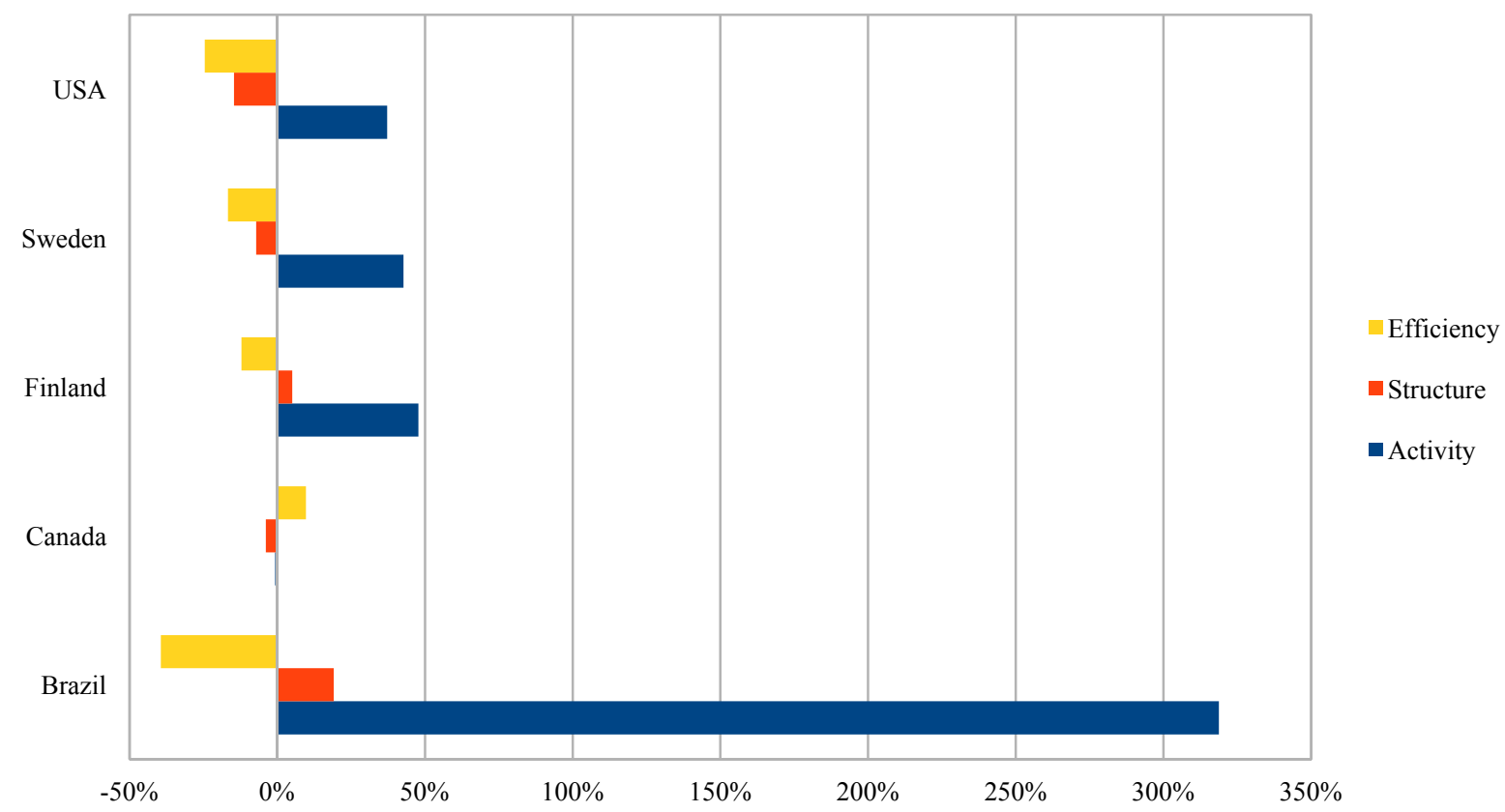

As stated above, the Canadian industry was the only one where there was a decrease in the energy efficiency level. The lesser efficiency was responsible for an additional primary energy consumption of $61.0 \mathrm{PJ}$, which is approximately $10 \%$ of its energy consumption in 1979. In the industries of USA, Brazil, Sweden and Finland, the higher energy efficiency levels were responsible for savings of 623.8 PJ (25\%), 48.9 PJ (39\%), 49.1 PJ (17\%), and 26.2 PJ (12\%), respectively.

The analysis showed that structural changes in both the Brazilian and Finnish sectors led to an increase of 23.7 PJ (19\%) and 11.0 PJ (5\%), respectively, in primary energy consumption. In the USA, Canada and Sweden, structural changes were responsible for primary energy savings of 373.4 PJ (15\%), 24.4 PJ (4\%) and 21.0 PJ (7\%), respectively.

The main changes in the Finnish production mix between 1979 and 2009 were the reduction of the newsprint share, from $26.4 \%$ to $2.0 \%$, and the rising share of the printing \& writing paper, from $32.7 \%$ to $62.7 \%$, in the overall paper production [30].

In the United States of America, the most significant structural change was the higher utilisation rate of recovered fibre, which rose from $24.5 \%$ in 1979 to $63.5 \%$ in 2009 [30].

In the Swedish pulp and paper sector, the printing \& writing production share increased from 15.3 to $26.7 \%$, while the "other papers" category share reduced from 6.3 to $1.1 \%$ over the analysed period. However, the most significant changes were the reduction of the chemical pulp share, from 76.0 to $69.9 \%$, leading to an increase in the mechanical pulp share, from $21.8 \%$ to $28.5 \%$. The rising recovered fibre utilisation rate, from 7.8 to $17.3 \%$, has also influenced the energy consumption significantly [30].

In Canada, the production of chemical pulp was belittled by the mechanical pulp. The share of chemical pulp decreased from $60.0 \%$ in 1979 to $52.1 \%$ in 2009 , while the mechanical pulp share increased from $37.9 \%$ to $46.9 \%$ in the same period. In Canadian paper production, the newsprint production share decreased from 64.6 to $34.1 \%$, while the printing \& writing share grew from 11.3 to 
$34.5 \%$. Another important structural change was the higher recovery fibre utilisation rate, which grew from 6.2 to $29.3 \%$ [30].

The influence of changes in the activity level was much higher in the Brazilian pulp and paper sector, where increases of $503 \%$ and $215 \%$ in pulp and paper production, respectively, were responsible for a 395.2 PJ (319\%) increase in the primary energy consumption from 1979 to 2009 . The higher activity level was also responsible for energy increases in the industries of the USA, Sweden, and Finland, respectively of 945.3 PJ (37\%), 125.7 PJ (43\%), and 103.3 PJ (48\%). In the USA, the pulp and paper production grew $7.3 \%$ (from 45.9 to 49.3 million tonnes) and $24.3 \%$ (from 57.4 to 71.4 million tonnes). The Swedish pulp and paper production increased 28.5\% (from 9.1 to 11.7 million tonnes) and $65.2 \%$ (from 6.5 to 10.8 million tonnes), respectively. In Finland, the pulp production grew $23.9 \%$ (from 7.1 to 8.7 million tonnes) and the paper production increased $84.8 \%$ (from 5.7 to 10.6 million tonnes). In Canada, both the pulp and paper production were lesser in 2009 than in 1979. In this period, the Canadian pulp production decreased approximately $11.7 \%$ (from 19.6 to 17.3 million tonnes) and the paper production reduced $4.9 \%$ (from 13.5 to 12.8 million tonnes). These production decreases led to a $4.5 \mathrm{PJ}$ savings in the primary energy consumption, which corresponds to $1 \%$ of the primary energy consumed in 1979 .

\subsection{Further Work}

Different production types are not in the same level of energy intensity in a country nor at world wide comparision. Changes in production from e.g., chemical pulp to mechanical pulp do create changes in energy efficiency index as it is currently defined. For more detailed analysis studying the same data with individual mill changes included would be an interesting further proposition.

As data issues are the main source of uncertainty of our study, industries entities, or even governments, should put an effort to improve quality and detail of data. If both higher quality and more detailed data was available, it would be possible to better estimate the effectiveness of different energy policies approach.

\section{Conclusions}

From 1979 to 2009 the Brazilian pulp and paper sector experienced a significant growth. In this period, the pulp production increased approximately 503\% (from 3.1 to 17.8 million tonnes) while paper production grew $215 \%$ (from 3.0 to 9.4 million tonnes). This increase in the production intensity of the country was the main factor of the rising energy consumption, influencing increases of $263.3 \mathrm{PJ}$ and 53.8 PJ in fuels and electricity consumption, respectively.

Even in a country, Brazil, with rapidly developing pulp and paper industry the often assumed global industrial energy efficiency improvement was not reached, but was at $0.67 \%$ level. More positively in studied main pulp and paper producing countries the same index varied between 0.8 and $0.6 \%$. It seems that even though the energy efficiency development is lower than often assumed the global $\mathrm{CO}_{2}$ reduction targets are reachable if the pulp and paper industry manages to still significantly reduce the fossil energy usage like it has done between 1979 and 2009. 
Although there were significant energy savings in fuels (38.9 PJ) and electricity (5.6 PJ) consumption due to higher efficiency in the sector, it was estimated there is still a potential reduction of 146.2 PJ and 7.8 PJ in fuels and electricity consumption, respectively.

From 2000 to 2009, the energy efficiency index related to the primary energy consumption increased from $67 \%$ to $76 \%$. This increase was influenced by the significant rising energy prices and the installation of very large new pulp mills, mainly in the first half of the decade.

Amongst the selected countries for comparison, both the Finnish and Swedish industries were the most energy efficient, with an energy efficiency index, 3-years average, of $89 \%$, followed by the Brazilian (75\%), the American (73\%) and the Canadian (62\%), the latter being the only one where there was a decrease in the energy efficiency level.

Considering an increase of $1 \%$ per year as a "normal rate" for the industrial sector, the annual increments of the energy efficiency levels were not as high as e.g., IEA predicts. The annual energy efficiency increase of the pulp and paper industries of the USA, Sweden, Brazil, and Finland were, respectively, $0.79 \%, 0.71 \%, 0.67 \%$, and $0.37 \%$. The Canadian energy efficiency decreased at an annual rate of $0.19 \%$ between 1979 and 2009 .

\section{Acknowledgments}

The authors thank to CAPES and to the Lappeenranta University of Technology for the support.

\section{References}

1. Patterson, M. What is energy efficiency? Concepts, indicators and methodological issues. Energy Policy 1996, 4, 377-390.

2. International Energy Agency (IEA). World Energy Outlook 2011; IEA: Paris, France, 2011.

3. Siitonen, S. Implications of Energy Efficiency Improvement for $\mathrm{CO}_{2}$ Emissions in Energy-Intensive Industry. Ph.D. Thesis, Aalto University, Helsinki, Finland, 2010.

4. Intergovernmental Panel on Climate Change (IPCC). IPCC Guidelines for National Greenhouse Gas Inventories; Prepared by the National Greenhouse Gas Inventories Programme; Eggleston, H.S., Buendia, L., Miwa, K., Ngara, T., Tanabe, K., Eds.; IGES: Hayama, Japan, 2006.

5. European Commission. Ecodesign for energy-using appliances. Available online: http://europa.eu/ legislation_summaries/other/132037_en.htm (accessed on 5 September 2012).

6. Worrell, E.; Bernstein, L.; Roy, J.; Price, L.; Harnisch, J. Industrial energy efficiency and climate change mitigation. Energy Effic. 2009, 2, 109-123.

7. Nagesha, N. Role of energy efficiency in sustainable development of small-scale industry clusters: An empirical study. Energy Sustain. Dev. 2008, 12, 34-39.

8. Phylipsen, D. Energy Efficiency Comparisons among Countries. In Encyclopedia of Physical Science and Technology, 3rd ed.; Meyers, R.A., Ed.; Academy Press: New York, NY, USA, 2003; pp. 433-440.

9. Asia-Pacific Economic Cooperation (APEC). Energy Efficiency Indicators: A Study of Energy Efficiency Indicators for Industry in APEC Economies; APEC: Tokyo, Japan, 2000. 
10. Bajay, S.V.; Gorla, F.D.; Bordoni, O.F.J.G. Os segmentos industriais energo-intensivos de maiores potenciais técnicos de conservação de energia no Brasil. Rev. Bras. Energ. 2009, 15, 89-107.

11. Eichhammer, W.; Mannsbart, W. Industrial energy efficiency. Energy Policy 1997, 25, 759-772.

12. Vakkilainen, E.; Kivistö, A. Energy Consumption Trends and Energy Consumption in Modern Mills in Forest Industry Production; Technical Report LUT/Energy-RR-10; LUT Energy: Lappeenranta, Finland, 2010.

13. De Beer, J.; Worrell, E.; Blok, K. Long-term energy-efficiency improvements in the paper and board industry. Energy 1998, 23, 21-42.

14. Farla, J.; Blok, K.; Schipper, L. Energy efficiency developments in the pulp and paper industry: A cross-country comparison using physical production data. Energy Policy 1997, 25, 745-758.

15. International Energy Agency (IEA). Tracking Industrial Energy Efficiency and $\mathrm{CO}_{2}$ Emissions; IEA: Paris, France, 2007.

16. European Commission. Reference Document on Best Available Techniques for Energy Efficiency; Joint Research Centre, Institute for Prospective Technological Studies: Seville, Spain, 2009.

17. Worrell, E.; Price, L.; Neelis, M.; Galitsky, C.; Nan, Z. World Best Practice Energy Intensity Values for Selected Industrial Sectors; Ernest Orlando Lawrence Berkeley National Laboratory: Berkeley, CA, USA, 2007.

18. Thollander, P.; Ottosson, M. An energy efficient Swedish pulp and paper industry-exploring barriers to and driving forces for cost-effective energy efficiency investments. Energy Effic. 2008, $1,21-34$.

19. Szabó, L.; Soria, A.; Forsström, J.; Keränen, J.T.; Hytönen, E. A world model of the pulp and paper industry: Demand, energy consumption and emission scenarios to 2030. Environ. Sci. Policy 2009, 12, 257-269.

20. Bachmann, D.L. Benchmarking Energético na Indústria de Celulose e Papel. (Energy Benchmarking in the Pulp and Paper Industry) [in Portuguese]. O Papel. 2009, 7, $72-76$.

21. American Institute of Chemical Engineers, Department of Energy. Pulp and Paper Industry Energy Bandwidth Study; Department of Energy's Industrial Technologies Program, American Institute of Chemical Engineers (AIChE): Atlanta, GA, USA, 2006.

22. Fleiter, T.; Eichhammer, W.; Hagemann, M.; Wietschel, M.; Hirzel, S. Energyefficiency in the German pulp and paper industry-A model-based assessment of saving potentials. Energy 2012, 40, 84-99.

23. Gilbreath, K.; Gupta, A.; Larson, E.D.; Nilsson, L.J. Energy Efficiency and the Pulp and Paper Industry; ACEEE American Council for an Energy-Efficient Economy: Washington, DC, USA, 1995.

24. Blum, O.; Maur, B.; Öller, H.-J. Revision of Best Available Technique Reference Document for the Pulp \& Paper Industry: Use of Energy Saving Techniques; TU Darmstadt-Fachgebiet Papierfabrikation und Mechanische Verfahrenstechnik: München, Germany, 2007.

25. Kilponen, L.; Ahtila, P.; Parpala, J.; Pihko, M. Improvement of Pulp Mill Energy Efficiency in an Integrated Pulp and Paper Mill-A Case Study; Publication of the Laboratory of Energy Economics and Power Plant Engineering, Helsinki University of Technology: Espoo, Finland, 2000. 
26. Klugman, S.; Karlsson, M.; Moshfegh, B. A. Scandinavian chemical wood pulp mill. Part 1. Energy audit aiming at efficiency measures. Appl. Energy 2007, 84, 326-339.

27. Wising, U.; Berntsson, T.; Åsblad, A. Usable excess heat in future Kraft pulp mills. Tappi J. 2002, 1, 121-127.

28. Åsblad, A.; Franck, P.-Å.; Berntsson, T. Learning from Experiences with Energy Conservation in the Pulp and Paper Industry; CADDET Analyses Series Report 28; CADDET Energy Efficiency: Sittard, The Netherlands, 2001.

29. Schumacher, K.; Sathaye, J. India's Pulp and Paper Industry, Productivity and Energy Efficiency; Ernest Orlando Lawrence, Berkeley National Laboratory, University of California: Berkeley, CA, USA, 1999.

30. Food and Agriculture Organization (FAO). Production, Import and Export Database of Forestry Products; FAO: Rome, Italy, 2011.

31. Michigan Merit Examination (MME). Balanço Energético Nacional 2011; MME: Brasília, Brazil, 2011.

32. Ministério do Desenvolvimento, Indústria e Comércio Exterior (MDIC). Balança Comercial Brasileira: Dados Consolidados; MDIC: Brasília, Brazil, 2010.

33. Ministério de Minas e Energia (MME). Balanço Energético Nacional 2006-Executive Summary; MME: Brasília, Brazil, 2006.

34. Ministério de Minas e Energia (MME). Balanço Energético Nacional-Complete Series; MME: Brasília, Brazil, 2011.

35. Velázquez, S.M.S.G. A Cogeração de Energia no Segmento de Papel e Celulose: Contribuição à Matriz Energética do Brasil. Master's Thesis, Universidade de São Paulo, São Paulo, Brazil, 2000.

36. Farla, J.; Blok, K. The quality of energy intensity indicators for international comparison in the iron and steel industry. Energy Policy 2001, 29, 523-543.

37. Ang, B.W. Decomposition methodology in industrial demand analysis. Energy 1995, 20, 1081-1095,

38. Karbuz, S. Achieving accurate international comparisons of manufacturing energy use data. Energy Policy 1998, 26, 973-979.

39. Tanaka, K. Assessment of energy efficiency performance measures in industry and their application for policy. Energy Policy 2008, 36, 2887-2902.

40. Farla, J. Energy consumption of pulp, paper and printing sectors. Personal communication, Utrecht, The Netherlands, 2011.

41. International Energy Agency (IEA). Electricity Information; IEA Statistics: Paris, France, 1995.

42. International Energy Agency (IEA). Electricity Information; IEA Statistics: Paris, France, 1996.

43. International Energy Agency (IEA). Electricity Information; IEA Statistics: Paris, France, 1998.

44. International Energy Agency (IEA). Electricity Information; IEA Statistics: Paris, France, 2000.

45. International Energy Agency (IEA). Electricity Information; IEA Statistics: Paris, France, 2002.

46. International Energy Agency (IEA). Electricity Information; IEA Statistics: Paris, France, 2005.

47. International Energy Agency (IEA). Electricity Information; IEA Statistics: Paris, France, 2007.

48. International Energy Agency (IEA). Electricity Information; IEA Statistics: Paris, France, 2009.

49. International Energy Agency (IEA). Electricity Information; IEA Statistics: Paris, France, 2011. 
50. Brazilian Association of Pulp and Paper Industry (BRACELPA). Installed capacity of Brazilian chemical pulp industry. Personal communication, 2011.

(C) 2012 by the authors; licensee MDPI, Basel, Switzerland. This article is an open access article distributed under the terms and conditions of the Creative Commons Attribution license (http://creativecommons.org/licenses/by/3.0/). 